\title{
Electrical Conductivity of Glass Fiber-Reinforced Plastic with Nanomodified Matrix for Damage Diagnostic
}

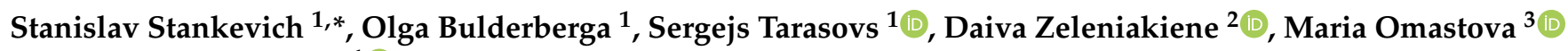 \\ and Andrey Aniskevich ${ }^{1}$ (D) \\ 1 Institute for Mechanics of Materials, University of Latvia, LV-1004 Riga, Latvia; olga.bulderberga@lu.lv (O.B.); \\ tarasov@pmi.lv (S.T.); andrey.aniskevich@pmi.lv (A.A.) \\ 2 Department of Mechanical Engineering, Kaunas University of Technology, 51424 Kaunas, Lithuania; \\ daiva.zeleniakiene@ktu.lt \\ 3 Polymer Institute, Slovak Academy of Sciences, 84541 Bratislava, Slovakia; maria.omastova@savba.sk \\ * Correspondence: Stanislav.Stankevich@lu.lv
}

\section{check for}

updates

Citation: Stankevich, S.;

Bulderberga, O.; Tarasovs, S.;

Zeleniakiene, D.; Omastova, M.;

Aniskevich, A. Electrical

Conductivity of Glass

Fiber-Reinforced Plastic with

Nanomodified Matrix for Damage

Diagnostic. Materials 2021, 14, 4485.

https://doi.org/10.3390/ma14164485

Academic Editors: Akif Kaynak and Ali Zolfagharian

Received: 29 June 2021

Accepted: 5 August 2021

Published: 10 August 2021

Publisher's Note: MDPI stays neutral with regard to jurisdictional claims in published maps and institutional affiliations.

Copyright: (c) 2021 by the authors. Licensee MDPI, Basel, Switzerland. This article is an open access article distributed under the terms and conditions of the Creative Commons Attribution (CC BY) license (https:// creativecommons.org/licenses/by/ $4.0 /)$.

\begin{abstract}
The electrical conductivity of glass fiber-reinforced plastic (GFRP) with epoxy matrix modified by multiwall carbon nanotubes (MWCNT) was studied. The electrical conductivity of nanomodified lamina and multi-layered GFRP was investigated on several levels using a structural approach. Components of the electrical conductivity tensor for unidirectional-reinforced monolayer were calculated similarly as in micromechanics using the conductivity of the nanomodified matrix. The electrical conductivity of multilayer composite was calculated using laminate theory and compared with values measured experimentally for various fiber orientation angles. Calculated and experimental data were in good agreement. The voltage distribution measured throughout the laminate allowed detecting the damage in its volume. The electrode network located on the laminate surface could determine the location, quantification, and geometry of the damage in the GFRP lamina modified with MWCNT. Experimental and calculated electrical resistance data for GFRP double-cantilever beam specimens were investigated in Mode I interlaminar fracture toughness test. Results demonstrate that electrical resistance could be successfully used for the diagnostic of the crack propagation during interlaminar fracture of the MWCNT-modified GFRP.
\end{abstract}

Keywords: glass fiber reinforced plastic; carbon nanotubes; electrical conductivity; micromechanics; damage diagnostic; voltage distribution; interlaminar fracture

\section{Introduction}

Glass fiber-reinforced plastic (GFRP) is originally an electrically non-conductive structural composite. Electrically conductive fillers, such as multiwall carbon nanotubes (MWCNT), graphene nanoplatelets, 2D carbides MXene, etc., can be incorporated at concentrations of less than $0.3 \mathrm{wt}$.\% into polymer matrixes of fiber-reinforced plastics to produce structural composites with enhanced mechanical performance and electrical conductivity [1-5]. For successful application of such advanced composite with specific electrical conductivity, it needs to be evaluated prior manufacturing process. The infill amount of MWCNT in the modified matrix, reinforcement angle, and stacking sequence of the laminated plate are the most crucial factors influencing the electrical conductivity of the composite [5-7]. Structural mechanic approach will be used for electrical conductivity prediction of MWCNT-modified GFRP plate. According to this approach, the addition of conductive MWCNT provided the conductivity of the epoxy matrix. Conductive matrix, in turn, provides conductivity of unidirectional monolayer with non-conductive fibers. Stack of conductive layers oriented in different angles provides conductivity of a multi-layered GFRP laminate. To predict the electrical conductivity of a nanomodified composite, the structural approach was approbated in [6] and additionally developed with various layups 
in [7]. However, the experimental and calculated electrical conductivity data did not agree for all layouts of composite plates.

Due to gained electrical conductivity, composites possess the ability for strain and damage monitoring [8-12]. As a result, many works were directed to create an internal health-monitoring system for composite structures by in situ measurements of electrical conductivity [8,13-17]. One of the monitoring methods can be performed by measuring the voltage distribution throughout the laminate with following damage detection in its volume. For nanomodified composite, voltage distribution monitoring can be achieved by applying the electrode network directly on top or inside the composite $[6,8,18]$. However, in most works, only the presence of damage is considered, without paying much attention to its location or geometry.

Fracture toughness plays an essential role in choosing composite materials for constructive applications. Adding carbon nanotubes to a multilayer composite not only helps to achieve the ability to monitor material damage but also significantly enhances its fracture toughness [19-22]. Damage diagnostic for interlaminar defects was approbated earlier for fiber-based composites [20,23-26]. The mentioned papers mostly focused on establishing the relationship between resistance and interlaminar crack propagation for double-cantilever beam (DCB) specimens during Mode I (opening mode) interlaminar fracture toughness test. In articles related to this method of detecting damage, experiments were mainly carried out on materials with high electrical conductivity, such as carbon fiber-reinforced plastic. As well, most of the methods were focused on damage monitoring at relatively high deformations.

Electrical resistance monitoring during structural damage of material gives an opportunity for health diagnostic of complex composite structures during its service time. However, considering the very high interest in the implementation of damage sensing technology inside the composite structures, the reliability of such a technique still remains inconsistent. Many damage diagnostic methods of nanomodified composites have not been thoroughly examined yet for successful approbation in extensively used modern applications.

The main aim of this study was to evaluate the possibility of electrical conductivity monitoring for damage diagnostic of GFRP with MWCNT nanomodified matrix. To achieve this aim following tasks were formulated: (1) To check the possibility of the electrical conductivity prediction of GFRP with nanomodified conductive matrix by the structural approach widely used for prediction of elastic properties of the composites; (2) to evaluate the electrical conductivity response of the nanomodified GFRP plate to a generated damage in its volume via characterization of the voltage distribution throughout the composite plate; (3) to check the correlation between electrical resistance response of nanomodified double-cantilever beam specimens with crack propagation during interlaminar fracture tests of the composite.

This research considered obtained results [6,7], shortcomings, and progress of previous works, and successfully applied the structural approach for prediction of the electrical conductivity of a multilayer composite including its different layup configurations. The location and geometry of the damage diagnostic in the composite plate was brought to the fore as part of the testing. Closer look was taken at the possibility of local diagnosis of damage at small deformations due to the introduction of thin conductive elements into the structure of the composite.

\section{Materials and Methods}

The GFRP composite under investigation was based on unidirectional (UD) glass fabric (GF) supplied by Havel Composites CZ Company Ltd. (Svésedlice, Czech Republic), and two-component epoxy resin system Biresin ${ }^{\circledR}$ CR122 was supplied by SIKA (Baar, Switzerland). MWCNT NC7000 ${ }^{\mathrm{TM}}$ supplied by Nanocyl SA (Sambreville, Belgium) was utilized as a stable nanofiller [27-29] for epoxy modification and spray-coating. The basic properties of the used materials are presented in Table 1. 
Table 1. Basic properties of used materials for composite preparation by manufacturers' data.

\begin{tabular}{cccc}
\hline Material & Parameter & Units & Value \\
\hline Epoxy resin Biresin ${ }^{\circledR} \mathrm{CR} 122$ & E-Modulus & $\mathrm{GPa}$ & $2.8[30]$ \\
MWCNT NC7000 & VM & $\Omega \cdot \mathrm{cm}$ & $1 \cdot 10^{-4}[31]$ \\
& Volume resistivity & $10^{-9} \mathrm{~m}$ & $9.5[31]$ \\
& Avg. diameter & $10^{-9} \mathrm{~m}$ & $1500[31]$ \\
Glass fabric by Havel Composites & Avg. length & $\mathrm{g} / \mathrm{m}^{2}$ & $500[32]$ \\
\hline
\end{tabular}

\subsection{Epoxy System Nanomodification}

High shear mixer DISPERMAT ${ }^{\circledR}$ LC30 was used to disperse directly added MWCNT in the volume of epoxy resin. A disk blade of $40 \mathrm{~mm}$ width at the speed of $10,000 \mathrm{rpm}$ was used to initiate the de-agglomeration process. The mixing procedure was carried out in the cold-water bath to avoid concentrate overheating. For the same reason, four mixing cycles of 10-15 min each were accomplished with 5-7 min pauses in-between. As far as cycles were over, the solution was degassed at a pressure of -0.98 bar and low speed mixed with hardener at 400-500 rpm to avoid excessive air injection in the matrix. The final $10 \mathrm{~min}$ degassing cycle was applied prior to specimen manufacturing.

Masterbatches with various MWCNT amounts were prepared to achieve matrix viscosity sufficient for its penetration through layers of GF. The resistivity of the examined nanomodified masterbatches is given in Figure 1.

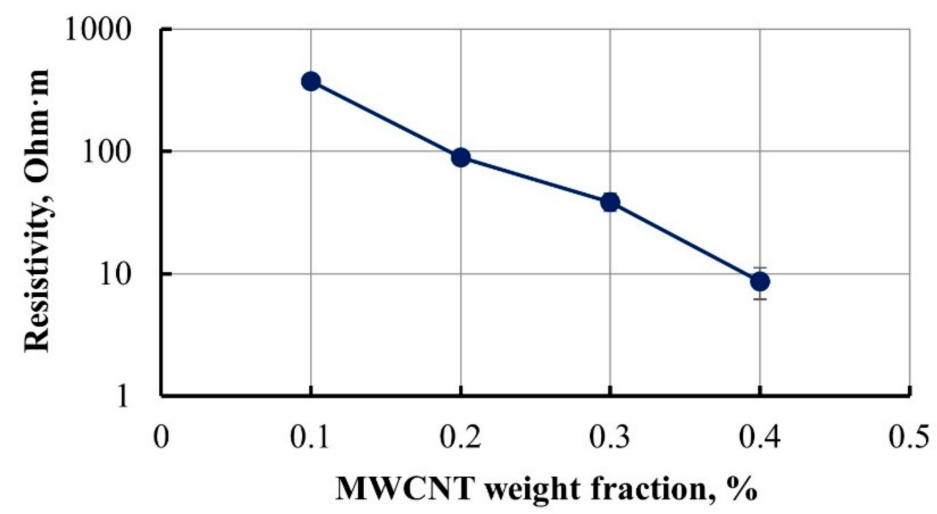

Figure 1. The resistivity of the epoxy matrix modified with different content of MWCNT.

The resistivity of the epoxy system strongly depends on MWCNT concentration level see Figure 1. At low MWCNTs concentration of $0.1 \mathrm{wt} . \%$, the electrical resistivity of epoxy had a significant drop down to the average of $370 \Omega \cdot \mathrm{m}$. Such electrical resistivity is in the lowest range for MWCNT-modified epoxy compared to other studies $[1,3,18]$. Resistivity difference up to several orders of magnitude was achieved with increasing of MWCNT weight fraction up to $0.4 \mathrm{wt} . \%$. Further increase of nanofiller concentration was not necessary, as well would be slightly handicapped due to the viscosity rise. The nanofiller concentration of $0.3 \mathrm{wt} . \%$ was chosen for composite matrix manufacturing.

The fracture surface of $0.2 \mathrm{wt} . \%$ MWCNT-modified epoxy is demonstrated in Figure 2. Separately located nanotubes and small agglomerates can be distinguished in the pictures, meaning that the nanofiller is quite well mixed in the binder. Good nanofiller dispersion contributes to the uniform distribution of electrically conductive tracks in the sample volume. 


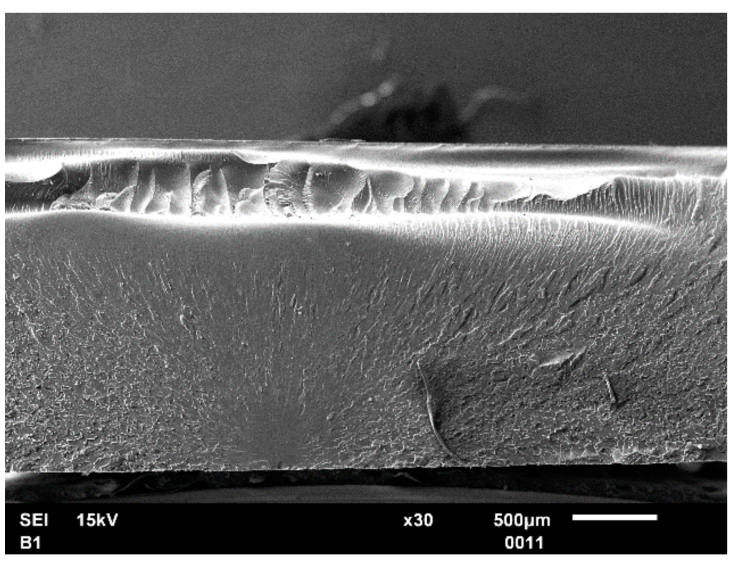

(a)

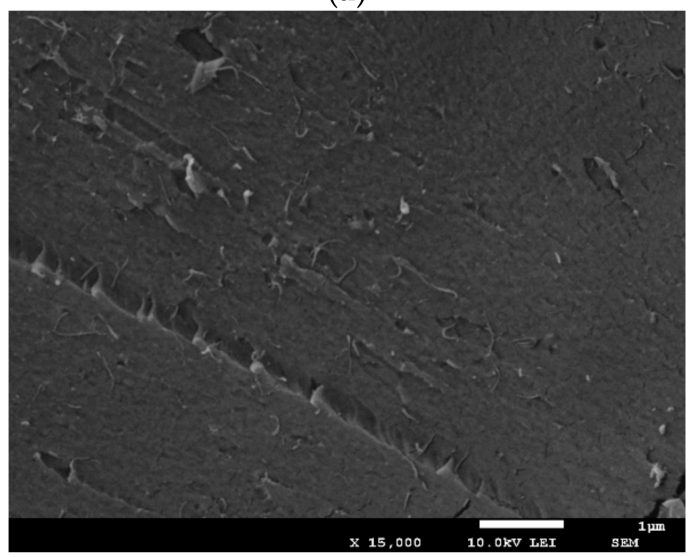

(c)

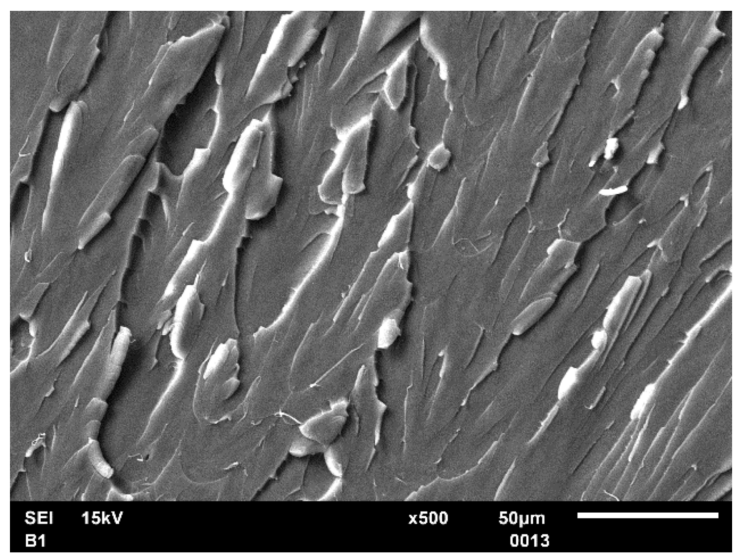

(b)

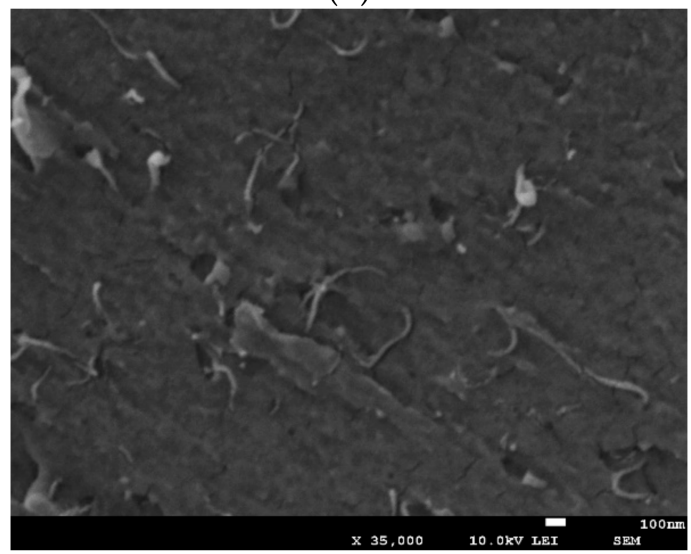

(d)

Figure 2. SEM micrographs of fracture surface of $0.2 \mathrm{wt} . \%$ MWCNT-modified epoxy at magnifications $30 \times(\mathbf{a}) ; 500 \times(\mathbf{b}) ;$ $15,000 \times(\mathbf{c}) ; 35,000 \times(\mathbf{d})$.

\subsection{Unidirectional and Cross-Ply Composite Lamination}

The unidirectional-reinforced composite laminate was prepared using the following procedure. GF layers were impregnated one by one with nanomodified epoxy resin between two polyethylene (PE) films. The resin was applied directly to the GF and covered with a top PE layer. The resin was evenly distributed within the GF sheet with randomly directed roller movements applied on the top of the PE film. After preparing the prepreg, they were sequentially laid on a waxed glass base. Once all layers were stacked, peel-ply and breathing net were applied on top of the last GF layer. The prepared stack was sealed using a vacuum bag. The vacuum of -0.98 bar was applied at the room temperature of $20^{\circ} \mathrm{C}$. The additional pressure of ca $0.012 \mathrm{MPa}$ was applied on top of the vacuum bag using weights. In such conditions, the vacuum bag was left for $18 \mathrm{~h}$ straight. The post-curing procedure was done according to epoxy system manufacturer recommendations: heating at rate $0.2{ }^{\circ} \mathrm{C} / \mathrm{min}$ until $110{ }^{\circ} \mathrm{C}$; keeping steady at $110{ }^{\circ} \mathrm{C}$ for $10 \mathrm{~h}$; cooling down at rate $-0.5^{\circ} \mathrm{C} / \mathrm{min}$ to avoid unexpected structural distortions due to the thermal shock. The volume fraction of GF in the composite specimens was kept at ca $68 \%$.

\section{Prediction of the Electrical Conductivity by the Structural Approach}

The electrical conductivity is a second rank tensor, and its components for unidirectionally reinforced monolayer were calculated similarly as in micromechanics using the conductivity of the nanomodified matrix. MWCNT-modified matrix is usually considered an isotropic material. A variety of models are applied to estimate its electrical conductivity depending on the content of conductive fillers $[7,27,33]$. To characterize the electrical conductivity of multi-layered composites, the conductivity of matrix, reinforcement angle, 
and stacking sequence of the laminated plate should be taken into account. For that reason, the structural approach that is widely used for the prediction of mechanical and thermal properties $[34,35]$ was adopted. According to such an approach, conductivity characterization of the multi-layered composite plate could be considered on several structural levels, from nanomodified epoxy matrix to complete stacked composite laminate.

\subsection{Micro-Scale of Composite}

A fiber-reinforced UD composite could be considered a set of long parallel glass fibers embedded in a polymer matrix at the micro-scale level Figure 3 [36].

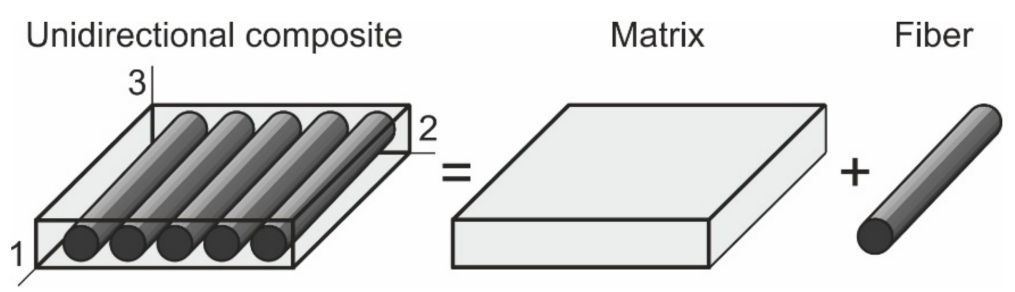

Figure 3. Scheme of a UD composite.

Considering the transversely isotropic symmetry of UD composite, its tensor of electrical conductivity $\sigma_{i j}$ in main axes of symmetry could be defined as follows:

$$
\sigma_{i j}=\left(\begin{array}{ccc}
\sigma_{11} & 0 & 0 \\
0 & \sigma_{22} & 0 \\
0 & 0 & \sigma_{33}
\end{array}\right)
$$

As long as UD GF are lined to axis 1 , it was assumed that $\sigma_{22}=\sigma_{33}$ thus two independent components fully define the material. The components $\sigma_{11}$ and $\sigma_{22}$ may be calculated using the rule of the mixture and already known equations from thermal conductivity, diffusivity, etc., [35]:

$$
\sigma_{11}=\eta \sigma_{11}^{f}+(1-\eta) \sigma^{m}
$$

and

$$
\sigma_{22}=\sigma^{\mathrm{m}}\left[1+\frac{\eta}{\sigma^{\mathrm{m}} /\left(\sigma_{22}^{f}-\sigma^{m}\right)+(1-\eta) / 2}\right]
$$

where $\eta$ is the volume fraction of glass fibers, $\sigma^{m}$ and $\sigma^{f}=0$ are conductivity for matrix and fibers, respectively.

\subsection{Monolayer}

The specific case needs to be evaluated to calculate the conductivity with GFRP orientation at a reinforcement angle $\theta$ rather than $0^{\circ}$, as shown in Figure 4.

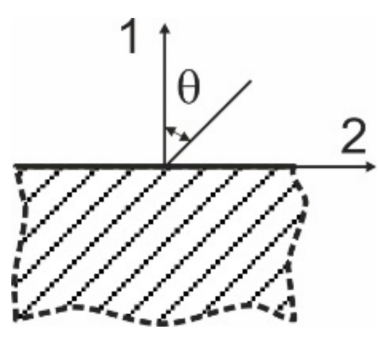

Figure 4. Notation of reinforcement angle in the material axes. 
Transformed conductivity tensor looks as following:

$$
\sigma_{k l}^{\prime}=\left(\begin{array}{ccc}
\sigma_{11}^{\prime} & \sigma_{12}^{\prime} & 0 \\
\sigma_{21}^{\prime} & \sigma_{22}^{\prime} & 0 \\
0 & 0 & \sigma_{33}^{\prime}
\end{array}\right)
$$

where $\sigma_{k l}^{\prime}=\sigma_{i j} \cos \left(\theta_{k i}\right) \cos \left(\theta_{l j}\right)$ (short form is used for tensor summation by indexes) with angles $\theta_{2^{\prime} 2}=\theta_{1^{\prime} 1}$. Components of the tensor could be written as

$$
\begin{aligned}
& \sigma_{11}^{\prime}=\sigma_{11} \cos ^{2} \theta+\sigma_{22} \sin ^{2} \theta \\
& \sigma_{22}^{\prime}=\sigma_{11} \sin ^{2} \theta+\sigma_{22} \cos ^{2} \theta
\end{aligned}
$$

and

$$
\sigma_{12}^{\prime}=\sigma_{21}^{\prime}=\left(\sigma_{22}-\sigma_{11}\right) \sin \theta \cos \theta
$$

Case of $\theta=45^{\circ}$, the components could be simplified to:

$$
\sigma_{11}^{\prime}=\frac{1}{2}\left(\sigma_{11}+\sigma_{22}\right) ; \quad \sigma_{22}^{\prime}=\frac{1}{2}\left(\sigma_{22}+\sigma_{11}\right) ; \quad \sigma_{12}^{\prime}=\frac{1}{2}\left(\sigma_{22}-\sigma_{11}\right)
$$

Relative conductivity $\sigma_{\text {rel }}$ could be expressed as:

$$
\sigma_{r e l}=\frac{\sigma_{11}^{\prime}(\theta)-\sigma_{22}}{\sigma_{11}-\sigma_{22}}
$$

The influence of the angle of reinforcement $\theta$ on composite relative conductivity is given in Figure 5.

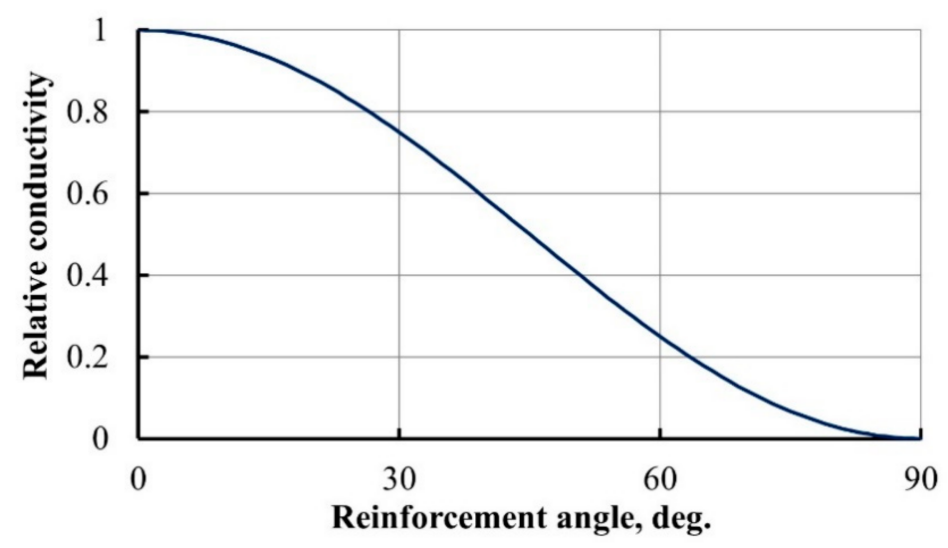

Figure 5. Dependence of relative conductivity on the angle of reinforcement.

As composite reinforcement was rotated from longitudinal to the transverse direction, the relative conductivity was changing gradually from 1 to 0 , as could be expected.

\subsection{Laminate}

Stack of conductive layers oriented in different angles provides conductivity of a multi-layered GFRP laminate as presented schematically in Figure 6. 


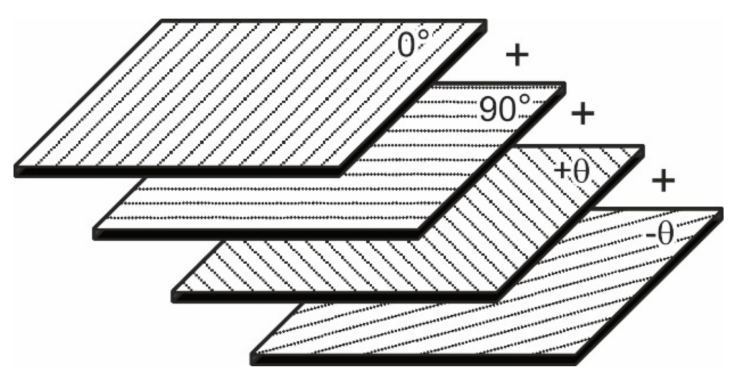

(a)

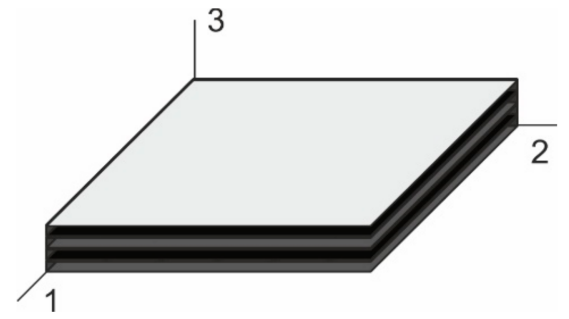

(b)

Figure 6. Lamination scheme: (a) Stacking of monolayers with angles 0,90 , and $\pm \theta^{\circ}$; (b) fully stacked laminate.

The investigated case represented three layup configurations $\left[0^{\circ}\right]_{8},\left[45^{\circ}\right]_{8}$, and $\left[90^{\circ}\right]_{8}$. For the $N$-layered lamina of thickness $H$, in-plane conductivity $\bar{\sigma}_{11}^{\prime}$ and $\bar{\sigma}_{22}^{\prime}$ was calculated using [7]

$$
\bar{\sigma}_{k l}^{\prime}=\frac{1}{H} \sum_{i=1}^{N} h_{i} \sigma_{k l(i)}^{\prime}
$$

Taking into account Equations (5)-(7), the tensor components of the lamina are the following:

$$
\bar{\sigma}_{11}^{\prime}=\frac{1}{H} \sum_{i=1}^{N} h_{i}\left(\sigma_{11} \cos ^{2} \theta_{i}+\sigma_{22} \sin ^{2} \theta_{i}\right)
$$

and

$$
\bar{\sigma}_{22}^{\prime}=\frac{1}{H} \sum_{i=1}^{N} h_{i}\left(\sigma_{11} \sin ^{2} \theta_{i}+\sigma_{22} \cos ^{2} \theta_{i}\right)
$$

For the specific layup $\left[ \pm \theta^{\circ}\right]_{4}$ conductivity tensor components were defined by the following simplified equations [7]:

$$
\bar{\sigma}_{11}^{\prime}=\sigma_{11} \cos ^{2} \theta+\sigma_{22} \sin ^{2} \theta \text { and } \bar{\sigma}_{22}^{\prime}=\sigma_{11} \sin ^{2} \theta+\sigma_{22} \cos ^{2} \theta
$$

If $\theta= \pm 45^{\circ}$, then:

$$
\bar{\sigma}_{11}^{\prime}=\frac{1}{2}\left(\sigma_{11}+\sigma_{22}\right) \text { and } \bar{\sigma}_{22}^{\prime}=\frac{1}{2}\left(\sigma_{22}+\sigma_{11}\right)
$$

Thus, Equation (14) allowed calculating conductivity for a specimen cut from a plate with $\theta= \pm 45^{\circ}$ layup.

\subsection{Verification}

To validate the prediction of electrical conductivity by the structural approach, calculated data were compared to the experimental ones on different structural levels. Nanomodified GFRP laminates were cut into 15 smaller specimens with dimensions of $50 \times 20 \times 3 \mathrm{~mm}$ in three separate groups with reinforcing angles 0,90 , and $45^{\circ}$. Electrical conductivity evaluation of those specimens was done using 2- and 4-point probe methods (denoted as 2 PPM and 4 PPM, respectively), which are mentioned in various papers $[37,38]$. Comparison of these two methods allows being aware of the effect of contact resistance between specimen and electrodes. Electrical contacts were created using conductive silver paint ELECTRON $40 \mathrm{AC}$. Multimeter Tektronix DMM 4020 was used for measurements.

The measurements by 2 PPM and 4 PPM were done for all three specimen groups of composite and nanomodified epoxy matrix. The results are presented in Figure 7. A two-fold difference in data obtained by those two methods was observed for some specimens, see Figure 7. Using 4 PPM, smaller electrical resistivity was obtained for all bar-type composite specimens with various angles of reinforcement. The 4 PPM method 
was used for resistivity measurement in all experiments further on where absolute values were necessary.

Electrical conductivity data calculated by Equations (11) and (12) were compared with experimentally acquired ones using the four-probe method in Figure 8.

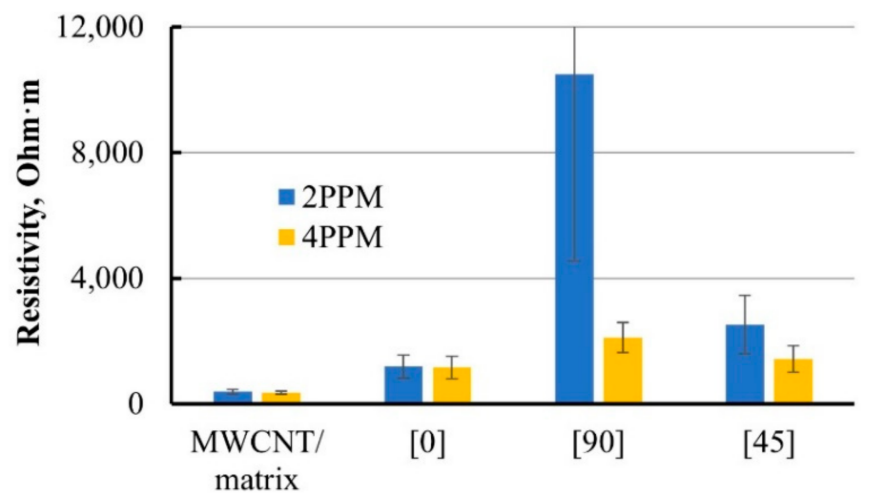

Figure 7. Comparison of 2- and 4-point probe methods (2 PPM and 4 PPM, respectively) for resistivity measurement of $0.3 \mathrm{wt} . \%$ MWCNT-modified matrix and its based composite bars with reinforcing angles $0^{\circ}, 90^{\circ}$, and $45^{\circ}$.

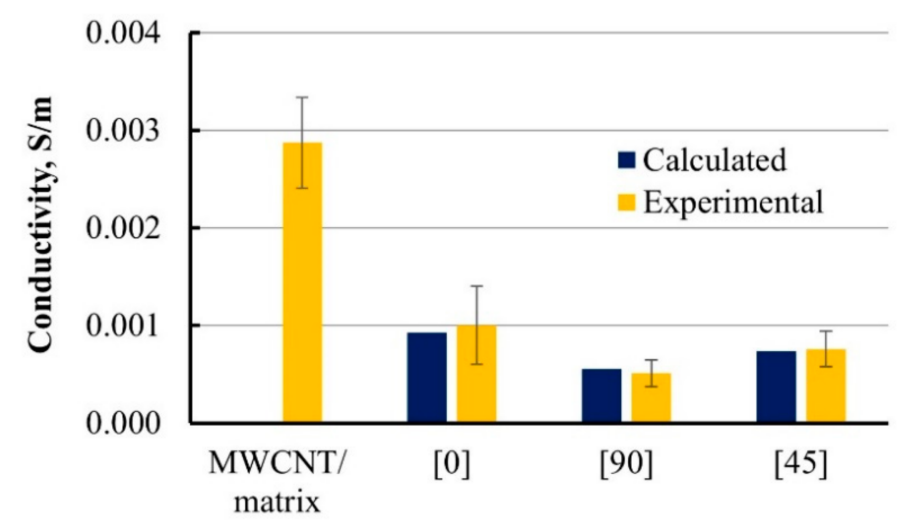

Figure 8. Calculated and experimental conductivity of UD GFRP with $0.3 \mathrm{wt}$.\% MWCNT-modified epoxy matrix and its based composite bars with reinforcing angles $0^{\circ}, 90^{\circ}$, and $45^{\circ}$.

Noticeable electrical anisotropy was observed for UD GFRP specimens modified by MWCNT due to the orientation of non-conductive fibers. Electrical conductivity values for composite along the fibers were two times higher than those for transverse direction. Even higher degree of anisotropy of one-order of magnitude was achieved in [15]. Such behavior was expected and could be described with a higher amount of obstacles for current to flow around created by transverse-orientated fibers. Calculated and experimental electrical conductivity data for various fiber orientation angles were in good agreement.

\section{Voltage Distribution in Damaged Nanomodified Composite Plate}

To evaluate the electrical conductivity usage for composite plate's damage diagnostic, MWCNT-modified composite plate with dimensions of $235 \times 235 \mathrm{~mm}$ was utilized. The reinforcement orientation of $\left[0^{\circ}, 90^{\circ}\right]_{4}$ was chosen for an equal conductivity in the $x$ and $y$ directions. For characterization of voltage distribution throughout the laminate, an electrode network of $8 \times 8$ contacts was formed by applying conductive paint on the polished top surface of the composite plate. The voltage of $20 \mathrm{~V}$ was applied between the diagonally opposite corners of the plate (upper left and lower right corners in Figure 9a). 


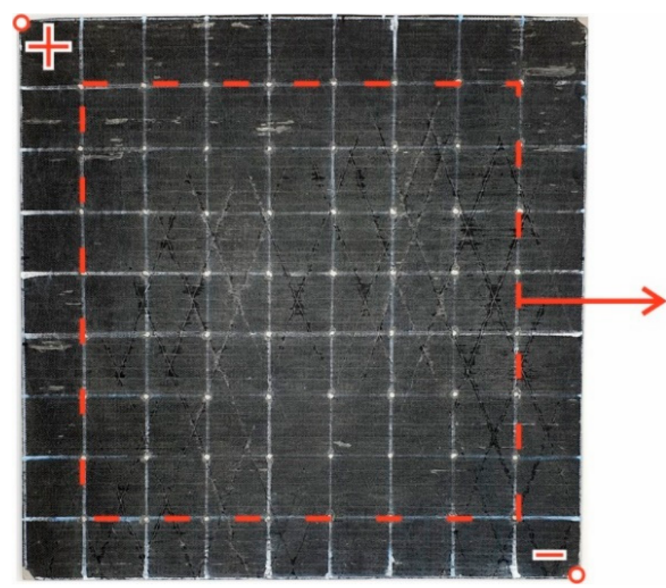

(a)

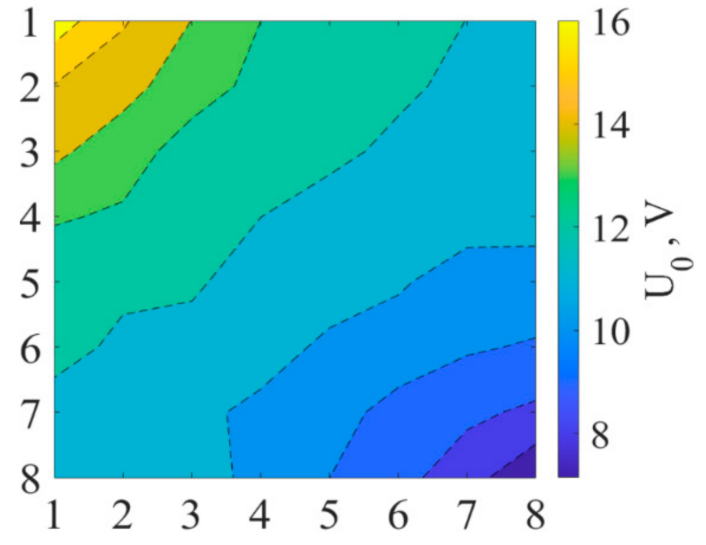

(b)

Figure 9. GFRP/MWCNT $\left[0^{\circ}, 90^{\circ}\right]_{4}$ undamaged composite plate (a) and experimentally obtained voltage distribution (b). Vertical and horizontal numbers from 1 to 8 define the coordinates of electrodes on the composite plate.

The voltage distribution was obtained by the voltage drop measuring on each contact for the initial undamaged state (later called case 0 in the text and Figure $9 \mathrm{~b}$ ).

Three different cases of damage were consecutively examined and presented in Figure 10: (1) A circular hole of diameter $9.8 \mathrm{~mm}$ in the middle; (2) a notch of $31 \mathrm{~mm}$ length and $1.8 \mathrm{~mm}$ width was added; (3) and one more notch of $70 \times 1.8 \mathrm{~mm}$ was added to the plate.

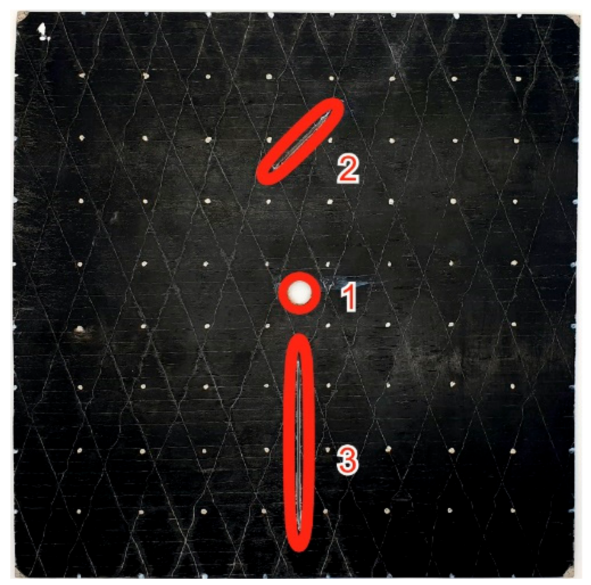

Figure 10. The GFRP/MWCNT composite plate with defects: hole (case 1) and notches (cases 2 and 3). Numbers show the sequence of the created defects.

Using the network of 64 contacts, the distribution of voltage in the GFRP plate was measured experimentally at each sequential damage state. The voltage field on contact points was registered at each state and compared with the previous one to observe the transformation of voltage distribution caused by the generated damage.

The distribution of the electric field potential in a plate for all damage states was simulated using two-dimensional isotropic static electric analysis by finite element method (FEM) in Ansys. The FEM was used to test and verify the accuracy of the electric potential measurements. Therefore simple 2D model with isotropic electric properties was applied. For evaluation of damage characterization capability by voltage distribution monitoring, experimental data were compared with the simulation model, as shown in Figure 11, for example, damage case (1), where $U_{i}$ with $i=0,1,2,3$ corresponds to the $i$-th state. To 
compare the disturbed electrical potential isolines, simulated results were recorded at the 64 points with the same coordinates and applied voltage as in the experiment.

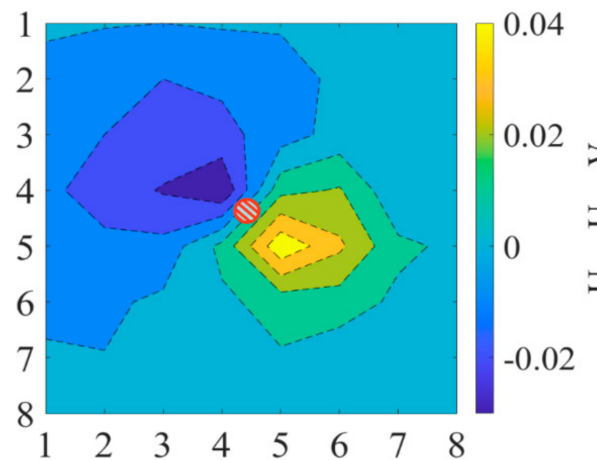

(a)

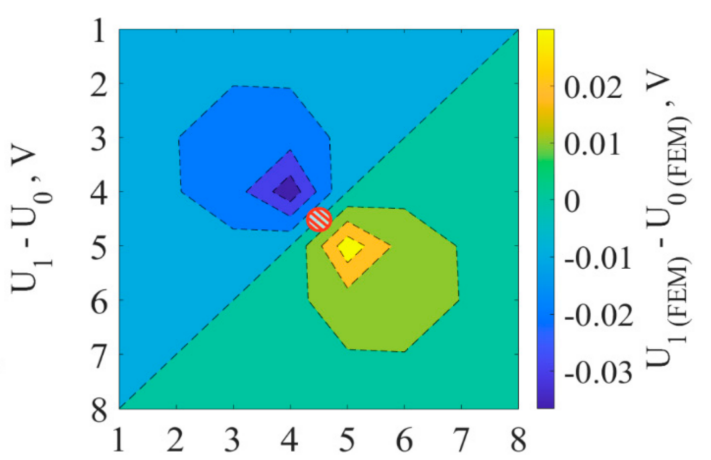

(b)

Figure 11. Experimental (a) and calculated using FEM (b) voltage distribution difference for the plate with the hole (case 1) and its undamaged state (case 0). Damaged areas are red line highlighted. Vertical and horizontal numbers from 1 to 8 define the coordinates of electrodes on the composite plate.

As seen from Figure 11, experimental and calculated voltage distribution affected by created defect had similar geometry and absolute values.

At every damage state of the plate, the highest voltage spikes occurred on the sides of the aperture along the potential lines. As seen from Figures 11 and 12, equipotential lines' front in the nearest area of the damage mimicked the geometry of the aperture. Thus, voltage distribution maps for all damage cases showed the aperture's proper position and geometry.

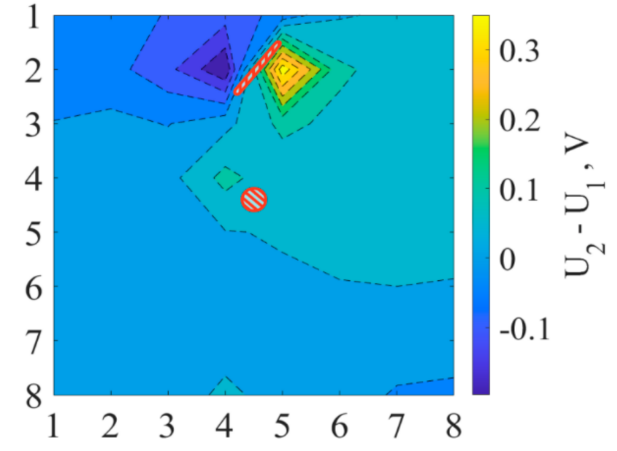

(a)

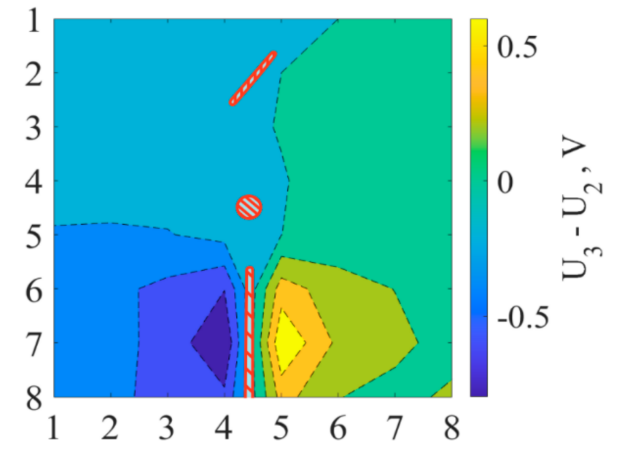

(b)

Figure 12. Experimentally obtained voltage distribution difference between the cases (2) and (1) (a), cases (3) and (2) (b). Damaged areas are red line highlighted. Vertical and horizontal numbers from 1 to 8 define the coordinates of electrodes on the composite plate.

Relative error $\delta$ between experimental and calculated data for different damage cases were found using

$$
\delta=\frac{1}{64} \sum_{i=1}^{64} \frac{\left|U_{\mathrm{FEM}}^{i}-U_{\mathrm{exp}}^{i}\right|}{U_{\exp }^{i}} \cdot 100 \%
$$

where $i$ is a consecutive number of composite plate's electrode. The average relative error of $6.2 \pm 0.2 \%$ for all states of the composite plate showed an excellent resemblance between calculated and experimental voltage data. Therefore, the generated damage of a plate could be predicted by the transformation of the voltage distribution in the laminate. 


\section{Delamination Crack Monitoring in Double-Cantilever Beams}

Electrical resistance response was used to characterize the interlaminar fracture of the composite. Two types of DCB specimens were used for this: (1) With nanomodified conductive matrix - electrical conductivity through all volume of a specimen was provided in this case; (2) with a neat matrix and MWCNT-modified interleave that provided conductivity of the thin layer only in the middle of a specimen. The crack during the test was intentionally initiated in this layer exactly.

DCB specimens were prepared according to the ASTM D5528 standard with dimensions of $125 \times 25 \times 3.0 \mathrm{~mm}$. DCB specimens were cut from the 8-layered UD GFRP plate prepared by the laminate stacking technique described in subsection 0. Polytetrafluorethylene (PTFE) film with a thickness of $8 \mu \mathrm{m}$ was added between the 4th and 5th layers that initiated interlaminar crack inside of the DCB specimen.

\subsection{Double-Cantilever Beam with Nanomodified Matrix}

Tests were performed according to the ASTM D5528 standard on a Zwick universal testing machine with a load cell of $2.5 \mathrm{kN}$ at a constant crosshead speed of $5 \mathrm{~mm} / \mathrm{min}$. Considering the conductive matrix of the MWCNT-modified GFRP, copper tape electrodes were placed directly on top of both polished sides of the DCB, Figure 13.

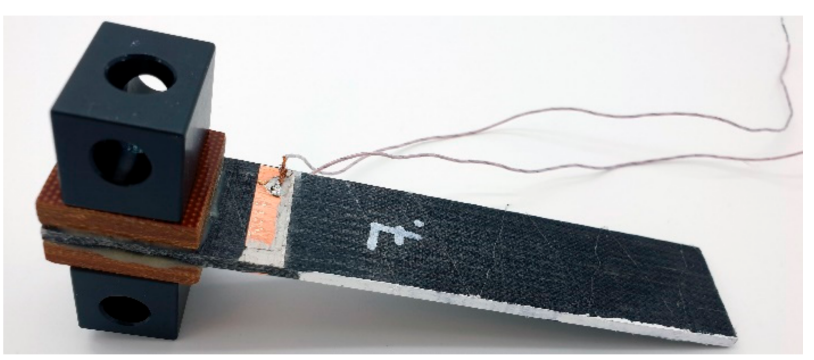

Figure 13. MWCNT-modified GFRP DCB specimen with attached copper electrodes, two glued tabs, and screwed loading blocks.

The electrical resistance of DCB specimens was monitored by the 2-point probe method during Mode I interlaminar fracture toughness test. Contact wires were welded to each side of the specimen to copper tape electrodes. Wires were connected to Zwick machine input. The electrical resistance of each specimen was measured prior to and during the crack opening phase, as shown in Figure 14.

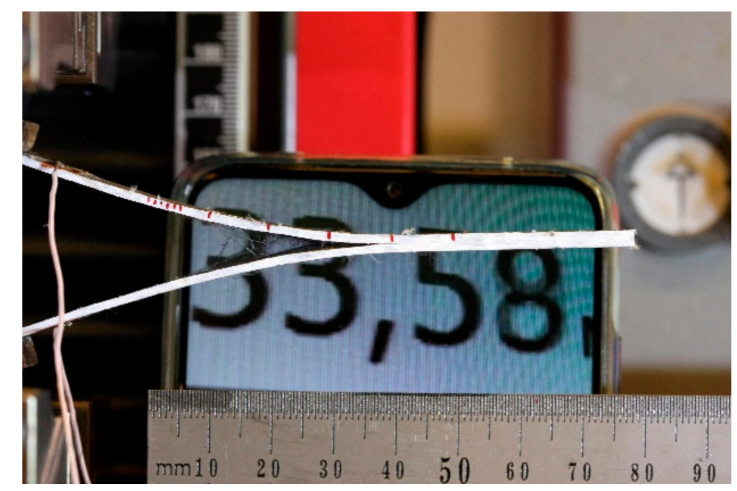

Figure 14. DCB specimen of GFRP with built-in foil electrodes during Mode I interlaminar fracture toughness test.

Optical and SEM images of DCB sample's fracture surface was obtained after testing, see Figure 15. Pieces of fractured epoxy can be still seen sticking to GF even after the test. 


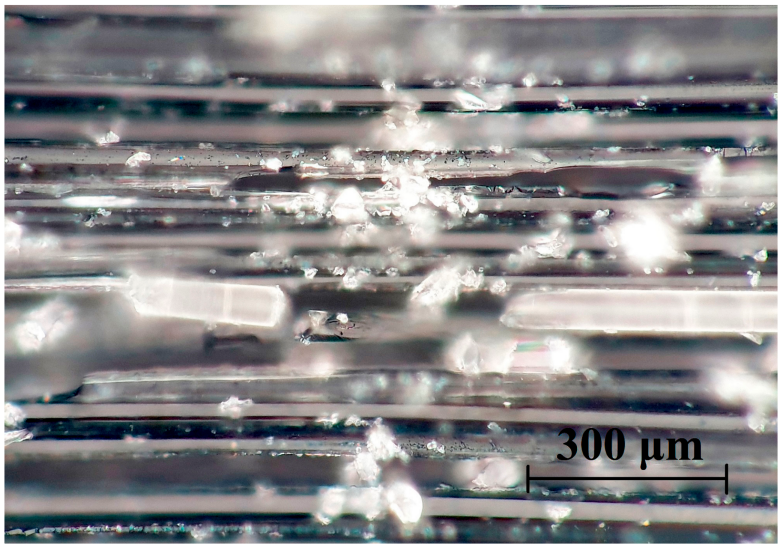

(a)

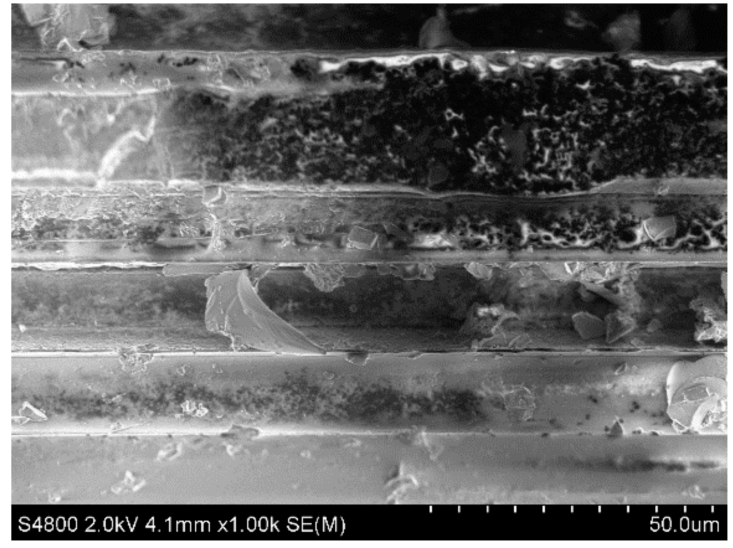

(b)

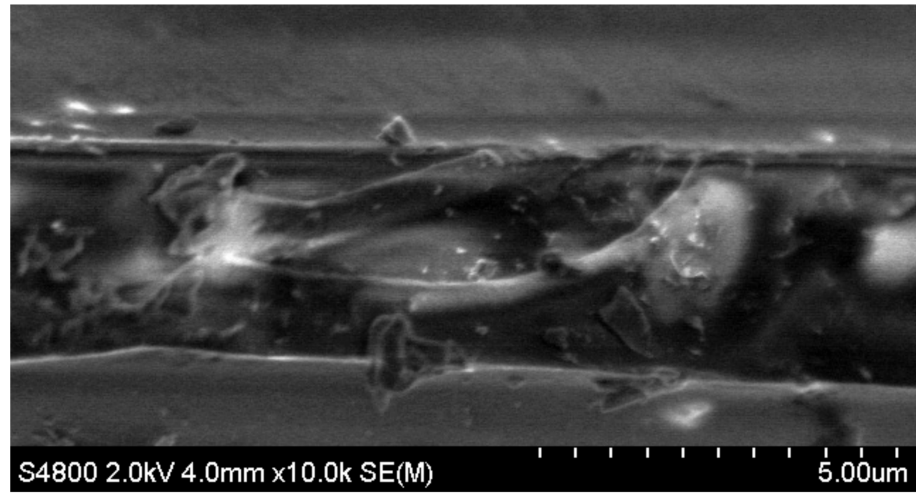

(c)

Figure 15. Optical (a) and SEM (b and $\mathbf{c})$ micrographs of fracture surface of nanomodified epoxy DCB sample after test. Magnifications: $500 \times(\mathbf{a}) ; 1000 \times(\mathbf{b}) ; 10,000 \times(\mathbf{c})$.

Fiber-matrix interface failure is the dominant failure mode in DCB specimens [24]. From Figure 15b it can be noticed that epoxy resin was locally stripped from the GF surface. However, nanotubes can be still seen holding to GF surface with some amount of matrix combined, see Figure 15c. MWCNT provides conductive tracks in the specimen volume but also helps the matrix to adhere to the fiber surface even under load. Fracture toughness is known to increase by $5-15 \%$ for composites with $0.1-0.5$ wt.\% of MWCNT [19,21].

Force-displacement data of three DCB specimens with nanomodified matrix are presented in Figure 16. Crack propagation distance was acquired from the photos obtained each $3 \mathrm{~s}$ during the test and synchronized with Zwick machine data in time.

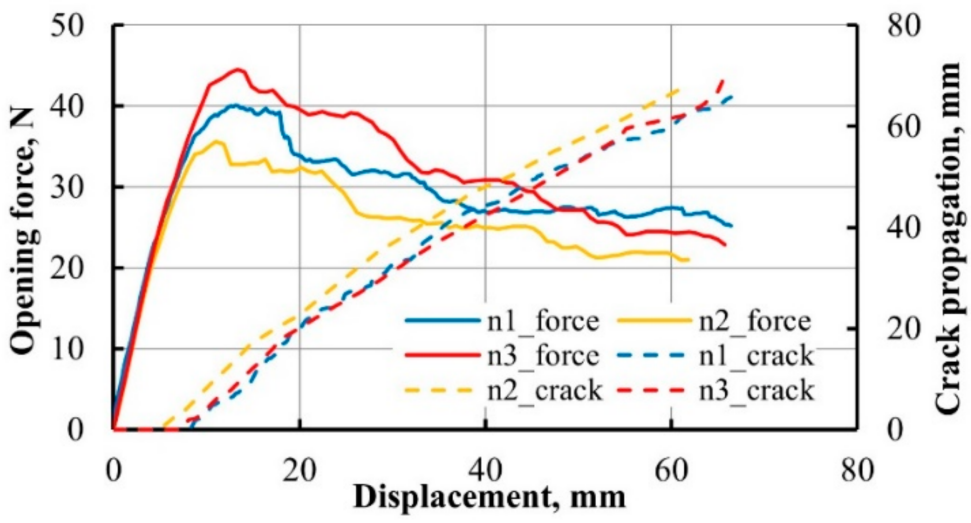

Figure 16. Opening force and crack propagation of DCB specimen vs. machine's grips displacement. 
A simplified model of three sequentially connected resistors was proposed to predict the crack propagation using electrical resistance of DCB specimen, see Figure 17.

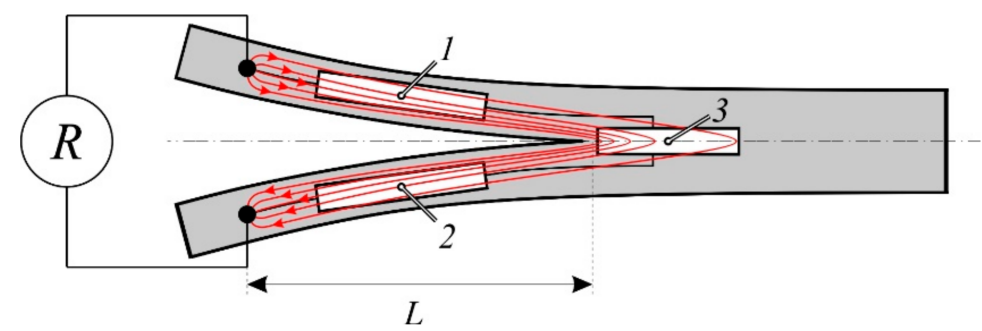

Figure 17. Schematic representation of DCB specimen during the Mode I interlaminar fracture toughness test. $L$ is the distance from connected electrodes to the tip of the crack. Sections 1, 2, and 3 represent the resistive volume of the specimen as sequentially connected resistors, and red lines schematically show the current flow.

Full resistance $R$ measured from electrode to electrode during a test was expressed as a sum of all resistors

$$
R(t)=R_{1}(t)+R_{2}(t)+R_{3}(t) ; \quad R_{1}(t)=R_{2}(t)
$$

where $R_{1,2}$ is the resistance of delaminated sections 1 and 2, which considered to be equal due to their identical geometry:

$$
L(t)=L_{1}(t)=L_{2}(t) ; S_{1}=S_{2}=\text { const }
$$

where $L_{1,2}$ and $S_{1,2}$ are the length and cross-section of sections 1 and 2, respectively. The resistance of sections 1 and 2 could be calculated using resistivity $\rho_{11}$ of the composite along the fiber direction:

$$
R_{1,2}=\frac{\rho_{11} L(t)}{S}
$$

Resistivity $\rho_{11}$ was measured independently for each specimen when sections 1 and 2 were fully separated after the test. The delaminated faces of the specimen open away from each other during the test, elongating the crack and sections 1 and 2. Within the presented model, section 3 was considered to have a constant resistance because it is supposed that the current with the highest density is located in the relatively small zone closest to the crack tip, as illustrated in Figure 17 with red lines. This zone in front of the crack propagates together with the crack, but the current density and resistivity remain unchanged in this area almost until the complete delamination of the specimen. Therefore, the resistance of section 3 could be found from the initial state of the specimen before the test as

$$
R_{3}=R(0)-2 \frac{\rho_{11} L(0)}{S}
$$

Keeping in mind that $R_{3}$ was assumed to be constant, total resistance can be fully defined with geometric parameters of sections 1 and 2. In this manner, total resistance during the delamination test could be calculated as follows:

$$
R(t)=2 \frac{\rho_{11} L(t)}{S}+R_{3}
$$

For verification of the presented model, experimental and calculated resistance data were compared with reference to DCB specimen crack propagation and given in Figure 18.

Calculated electrical resistance showed a similar increase as experimental during the crack propagation. The presented simplified model appeared to have adequate prediction 
repeatability through various test specimens. The difference between resistance absolute values for different specimens was caused by their resistivity variation before the tests.

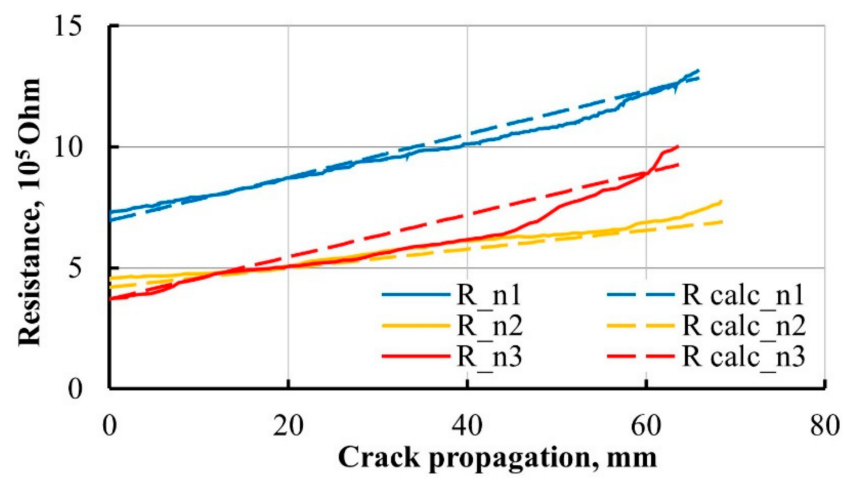

Figure 18. Experimental (solid line) and calculated (dashed line) electrical resistance of MWCNTmodified 8-layered GFRP composite DCB during Mode I interlaminar fracture toughness test.

\subsection{DCB with Nanomodified Interleave}

With volumetric matrix nanomodification, only integral damage diagnostic can be provided in all specimen's volume. Thus, the whole structural element is a single sensor, and in that case, damage localization is impossible. The situation changes with the embedding of multiple conductive sensors to the structural element. This can be realized via the implementation of several conductive interleaves. Interleave can be created by spray-coating of conductive nanoparticles during manufacturing of the structural element. To verify this concept and develop technology of interleaved composite manufacturing, GFRP plate with a neat epoxy matrix and single conductive interleave was produced. Interleave consisted of two woven GF layers with an area density of $130 \mathrm{~g} / \mathrm{m}^{2}$ supplied by Havel Composites CZ Company Ltd., and a spray-coated layer of MWCNT between them. The spray-coating procedure was carried out using MWCNT-acetone solution by spray-gun SAP-CR 0.2 supplied by STAR ${ }^{\circledR}$, with a nozzle size of $0.2 \mathrm{~mm}$ at the pressure of $0.1 \mathrm{MPa}$. The solution was prepared using an ultrasonic probe sonicator at $120 \mathrm{~W}$ for $1 \mathrm{~h}$ with three 5-min pauses in-between. The amount of MWCNT in mass per area was held at $2.3 \cdot 10^{-4} \mathrm{mg} / \mathrm{mm}^{2}$ during the spray-coating procedure. Each of the two GF layers was one side spray-coated, and a foil electrode was attached at one end. These two layers were stacked with sprayed sides face to face, as presented in Figure 19. PTFE film was placed in between for the crack initiation and proper initial resistance monitoring.

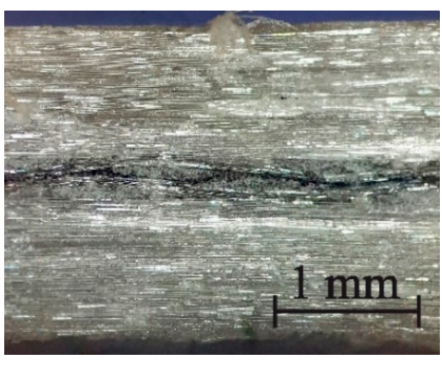

(a)

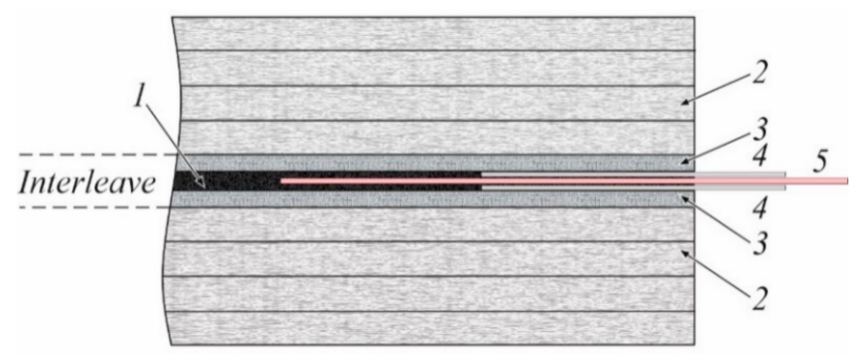

(b)

Figure 19. Eight-layered UD GFRP composite plate with the interleave. Micro photo of the longitudinal cross-section with magnification $200 \times($ a) and the laminate structure (b). The spray-coated layer of MWCNT (1); UD glass fibers (2); woven glass fibers (3); aluminum foil electrode (4); PTFE film (5).

Electrical resistance data of DCB between two electrodes were collected by the Zwick machine during Mode I interlaminar fracture toughness test and synchronized in time with opening force applied to the specimen. Combined force and relative resistance data in time interval 150-350 s during the crack propagation are given in Figure 20. 


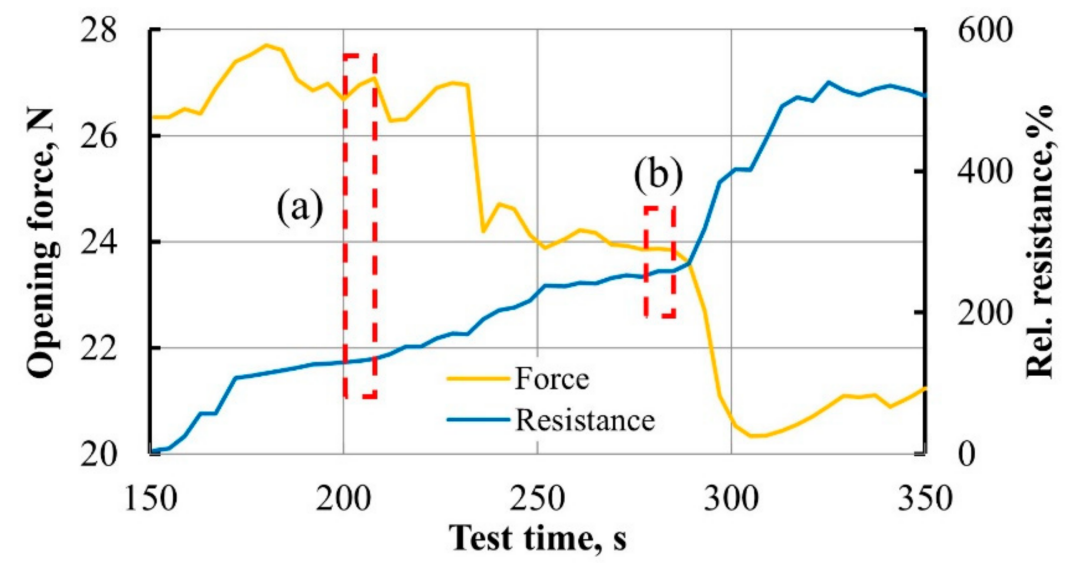

Figure 20. The opening force $F$ and relative resistance $R_{r e l}$ in time during crack propagation for neat epoxy-based DCB specimens with MWCNT spray-coated interleave. Red sectors (a) and (b) are examined in Figure 21.

Correlation coefficient $r$ [39] was calculated to evaluate the relationship between the force applied to DCB specimen and its resistance.

$$
\begin{gathered}
r=\frac{\sum(F(t)-\bar{F})\left(R_{r e l}(t)-\bar{R}_{r e l}\right)}{\sqrt{\sum(F(t)-\bar{F})^{2} \Sigma\left(R_{r e l}(t)-\bar{R}_{r e l}\right)^{2}}} \\
R_{r e l}(t)=\frac{R(t)-R(t=0)}{R(t=0)} \cdot 100
\end{gathered}
$$

where $F(t)$ is the opening force measured in time, $R_{r e l}(t)$ is relative resistance, $\bar{F}$ and $\bar{R}_{r e l}$ are mean values for opening force and relative resistance within the examined time interval.

The correlation value of $r=-0.945$ indicates a very strong negative connection between the two processes. The applied force caused DCB delamination process, which showed a great effect on specimen resistance. Some unsynchronized variations between the two parameters were observed during the experiment. This potentially may have occurred due to delamination of the conductive sprayed layer and the specimen. Therefore conductive paths were not broken even during the crack propagation.

The more detailed characterization was provided at much shorter time intervals to estimate the resistance response to small force adjustments. For that reason, two random intervals of $5 \mathrm{~s}$ were taken for examination. Two parameters $\Delta F=F_{n}-F_{n-1}$ and $\Delta R_{\text {rel. }}=$ $R_{\text {rel. } n}-R_{\text {rel. } n-1}$ were analyzed and presented in Figure 21.

Obtained results showed a good connection between force and resistance values during the experiment at small force adjustments. Each force jump that occurred in the crack propagation, even within the margins of $\pm 0.015 \mathrm{~N}$, was followed by a jump of resistance. As could be seen from Figure 21, resistance response became higher during the test.

Such behavior could be described by a large number of defects in the conductive layer after delamination, see Figure 22, which led to resistance rise. Therefore, following crack propagation would have a more substantial effect on resistance until the complete conductivity loss. Figure 22 illustrates the degradation of the MWCNT conductive layer during the test. Examining the fracture surface, it can be seen that the surface of the electrically conductive layer is not uniform after the degradation process. Intermittent destruction of the conducting layer leads to sharp jumps of resistance, and at the same time, a huge decrease of electrical conductivity occurred up to its complete loss. To avoid such sudden signal interruption, the thickness and strength of the nanofiller layer should be improved to conduct the signal until the total delamination. For this, upper and lower half of the interleave could be both sides spray-coated or fully dipped in a MWCNT solution. 
In that case, the inner side of each GF will be fully covered with nanotubes, even during the test.

(a)

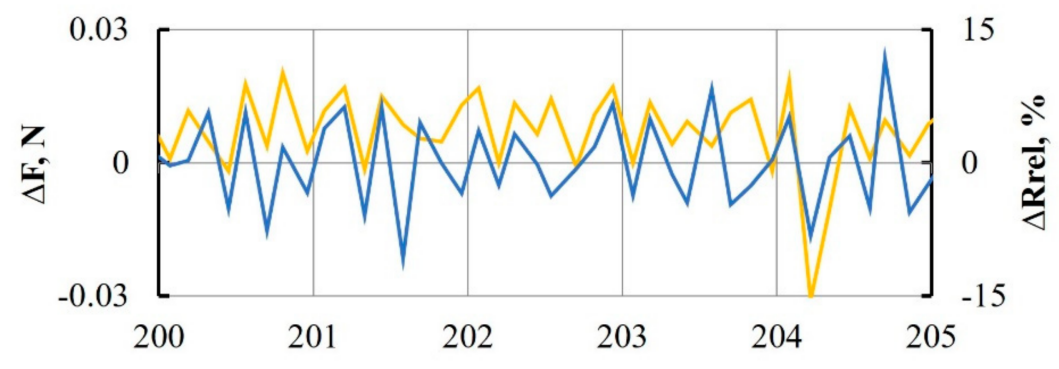

(b)

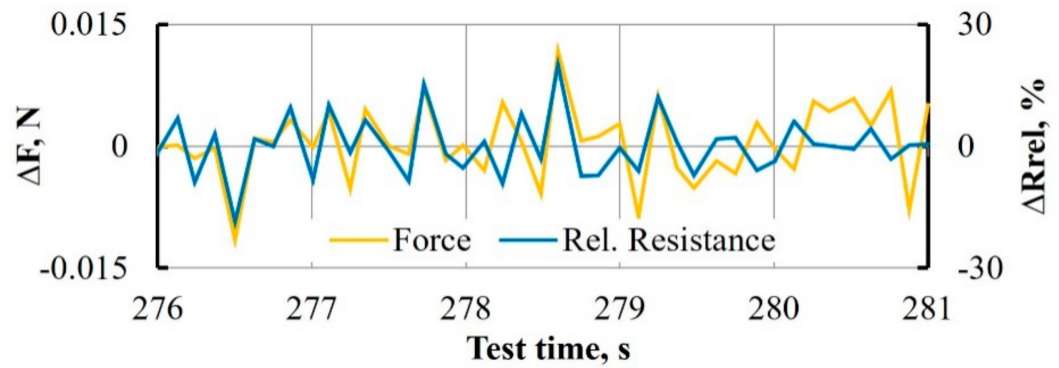

Figure 21. Parameters $\Delta F$ and $\Delta R_{\text {rel. }}$ in time intervals of 200-205 (a) and 276-281 s (b) during crack propagation for neat epoxy-based DCB specimen with MWCNT spray-coated interleave.

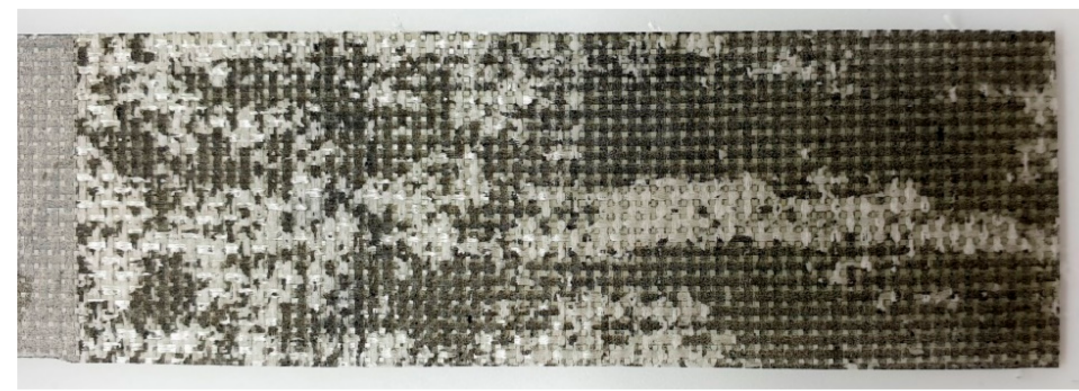

Figure 22. The surface of fractured epoxy-based DCB specimen with MWCNT spray-coated interleave after delamination.

\section{Conclusions}

1. It was experimentally proved that electrical conductivity monitoring could be successfully used for open and interlaminar damage diagnostic of the GFRP lamina with the MWCNT-doped polymer matrix.

2. The electrical conductivity of the GFRP composite was experimentally and theoretically considered on different structural levels. The addition of conductive MWCNT provided the conductivity of the epoxy matrix. Conductive matrix, in turn, provides conductivity of unidirectional monolayer with non-conductive fibers. Stack of conductive layers oriented in different angles provides conductivity of a multi-layered GFRP laminate. Well-known equations were applied to calculate the conductivity of the composite on these structural levels. Calculated and experimental electrical conductivities of multi-layered GFRP with MWCNT-modified epoxy matrix are in good agreement.

3. Determining the location, quantification, and geometry of the damage in the MWCNTmodified GFRP lamina can be performed by monitoring the voltage distribution throughout the composite plate. The shape of equipotential voltage lines near the defect in the plate was precisely mimicking the geometry of the defect. Furthermore, voltage distribution in damaged GFRP plate calculated by FEM showed an excellent resemblance with the experimental data for all damage states. 
4. Monitoring the electrical resistance can be successfully used to control the crack propagation, as shown for interlaminar fracture tests of the GFRP with epoxy matrix modified by MWCNT in volume. A simple model was proposed to calculate the volume resistance of the DCB specimens in the tests. Calculated and experimental electrical volume resistance showed similar behavior during the whole time interval of the crack propagation.

5. Experimental results prove that adequate damage localization in the GFRP plate was implemented by introducing thin conductive MWCNT-based interleave in the mid-plane of the composite. Furthermore, obtained results indicated a very strong negative correlation between the opening force, the interleave resistance, and the crack propagation.

Author Contributions: Conceptualization, S.S. and A.A.; Methodology, S.S., S.T. and A.A.; Validation, S.S., O.B., S.T., D.Z., M.O. and A.A.; Formal Analysis, S.S.; Investigation, S.S.; Writing - Original Draft Preparation, S.S.; Writing - Review \& Editing, S.S., O.B., S.T., D.Z., M.O. and A.A.; Supervision, A.A. All authors have read and agreed to the published version of the manuscript.

Funding: Work developed under the M-ERA.Net research project NANO2COM-Advanced Polymer Composites Filled with Novel 2D Nanoparticles. The research was funded by grants No. 1.1.1.5/ERANET/18/02 from Latvian State Education Development Agency, No. S M ERA.NET-181 from the Research Council of Lithuania, and No. M-ERANET-18-414-Nano2Com from Slovak Academy of Sciences.

Institutional Review Board Statement: Not applicable.

Informed Consent Statement: Not applicable.

Data Availability Statement: Study did not report any data.

Conflicts of Interest: The authors declare no conflict of interest.

\section{References}

1. Kranauskaite, I.; Macutkevic, J.; Borisova, A.; Martone, A.; Zarrelli, M.; Selskis, A.; Aniskevich, A.; Banys, J. Enhancing electrical conductivity of multiwalled carbon nanotube/epoxy composites by graphene nanoplatelets. Lith. J. Phys. 2018, 57. [CrossRef]

2. Böger, L.; Wichmann, M.H.G.; Meyer, L.O.; Schulte, K. Load and health monitoring in glass fibre reinforced composites with an electrically conductive nanocomposite epoxy matrix. Compos. Sci. Technol. 2008, 68, 1886-1894. [CrossRef]

3. Mehdipour, A.; Rosca, I.; Trueman, C.; Sebak, A.; Hoa, S. Multiwall Carbon Nanotube-Epoxy Composites With High Shielding Effectiveness for Aeronautic Applications. IEEE Trans. Electromagn. Compat. 2012, 54, 28-36. [CrossRef]

4. Kilikevičius, S.; Kvietkaite, S.; Mishnaevsky, L., Jr.; Omastová, M.; Aniskevich, A.; Zeleniakienè, D. Novel Hybrid Polymer Composites with Graphene and MXene Nano-Reinforcements: Computational Analysis. Polymers 2021, 13, 1013. [CrossRef]

5. Gojny, F.H.; Wichmann, M.H.G.; Fiedler, B.; Bauhofer, W.; Schulte, K. Influence of nano-modification on the mechanical and electrical properties of conventional fibre-reinforced composites. Compos. Part A Appl. Sci. Manuf. 2005, 36, 1525-1535. [CrossRef]

6. Aniskevich, A.; Starkova, O. Structural Mechanic Approach for Prediction of Electrical Conductivity of Glass Fibre Reinforced Composite with Cnt-Modified Epoxy Matrix. In Proceedings of the 21st International Conference on Composite Materials, Xi'an, China, 20-25 August 2017.

7. Aniskevich, A.; Stankevich, S.; Sevcenko, J. Prediction method of electrical conductivity of nano-modified glass fibre reinforced plastics. IOP Conf. Ser. Mater. Sci. Eng. 2019, 500, 012010. [CrossRef]

8. Schueler, R.; Joshi, S.P.; Karl, S. Damage detection in CFRP by electrical conductivity mapping. Compos. Sci. Technol. 2001, 61, 921-930. [CrossRef]

9. Wen, J.; Xia, Z.; Choy, F. Damage detection of carbon fiber reinforced polymer composites via electrical resistance measurement. Compos. Part B Eng. 2011, 42, 77-86. [CrossRef]

10. Viets, C.; Kaysser, S.; Schulte, K. Damage mapping of GFRP via electrical resistance measurements using nanocomposite epoxy matrix systems. Compos. Part B Eng. 2014, 65, 80-88. [CrossRef]

11. Monastyreckis, G.; Stepura, A.; Soyka, Y.; Maltanava, H.; Poznyak, S.; Omastová, M.; Aniskevich, A.; Zeleniakienè, D. Strain Sensing Coatings for Large Composite Structures Based on 2D MXene Nanoparticles. Sensors 2021, 21, 2378. [CrossRef] [PubMed]

12. Thostenson, E.; Chou, T.-W. Real-time in situ sensing of damage evolution in advanced fiber composites using carbon nanotube networks. Nanotechnology 2008, 19, 215713. [CrossRef] [PubMed]

13. Thostenson, E.; Chou, T.W. Carbon Nanotube Networks: Sensing of Distributed Strain and Damage for Life Prediction and Self Healing. Adv. Mater. 2006, 18, 2837-2841. [CrossRef] 
14. Gao, L.; Chou, T.-W.; Thostenson, E.; Zhang, Z.; Coulaud, M. In situ sensing of impact damage in epoxy/glass fiber composites using percolating carbon nanotube networks. Carbon 2011, 49, 3382-3385. [CrossRef]

15. Fiedler, B.; Gojny, F.; Wichmann, M.; Bauhofer, W.; Karl, S. Can carbon nanotubes be used to sense damage in composites? Eur. J. Control. 2004, 29, 81-94. [CrossRef]

16. Alexopoulos, N.D.; Bartholome, C.; Poulin, P.; Marioli-Riga, Z. Structural health monitoring of glass fiber reinforced composites using embedded carbon nanotube (CNT) fibers. Compos. Sci. Technol. 2010, 70, 260-271. [CrossRef]

17. Georgousis, G.; Pandis, C.; Kalamiotis, A.; Georgiopoulos, P.; Kyritsis, A.; Kontou, E.; Pissis, P.; Micusik, M.; Czanikova, K.; Kulicek, J.; et al. Strain sensing in polymer/carbon nanotube composites by electrical resistance measurement. Compos. Part $B$ Eng. 2015, 68, 162-169. [CrossRef]

18. Castellino, M.; Chiolerio, A.; Shahzad, M.I.; Jagdale, P.; Tagliaferro, A. Electrical conductivity phenomena in an epoxy resincarbon-based materials composite. Compos. Part A 2014, 61, 108-114. [CrossRef]

19. Karapappas, P.; Vavouliotis, A.; Tsotra, P.; Kostopoulos, V.; Paipetis, A. Enhanced Fracture Properties of Carbon Reinforced Composites by the Addition of Multi-Wall Carbon Nanotubes. J. Compos. Mater. 2009, 43, 977-985. [CrossRef]

20. Shin, Y.C.; Lee, W.I.; Kim, H.S. Mode II interlaminar fracture toughness of carbon nanotubes/epoxy film-interleaved carbon fiber composites. Compos. Struct. 2020, 236, 111808. [CrossRef]

21. Kepple, K.L.; Sanborn, G.P.; Lacasse, P.A.; Gruenberg, K.M.; Ready, W.J. Improved fracture toughness of carbon fiber composite functionalized with multi walled carbon nanotubes. Carbon 2008, 46, 2026-2033. [CrossRef]

22. Li, W.; Xiang, D.; Wang, L.; Harkin-Jones Freng, E.; Zhao, C.; Wang, B.; Li, Y. Simultaneous enhancement of electrical conductivity and interlaminar fracture toughness of carbon fiber/epoxy composites using plasma-treated conductive thermoplastic film interleaves. RSC Adv. 2018, 8, 26910-26921. [CrossRef]

23. Zhang, H.; Liu, Y.; Kuwata, M.; Bilotti, E.; Peijs, T. Improved fracture toughness and integrated damage sensing capability by spray coated CNTs on carbon fibre prepreg. Compos. Part A Appl. Sci. Manuf. 2015, 70, 102-110. [CrossRef]

24. Wan, Y.; Yang, H.; Tian, Z.; Yang, B.; Xian, G.; Weng, J.; Chen, S.; Ding, X.; Luo, W. Mode I interlaminar crack length prediction by the resistance signal of the integrated MWCNT sensor in WGF/epoxy composites during DCB test. J. Mater. Res. Technol. 2020, 9 , 5922-5933. [CrossRef]

25. Todoroki, A. The effect of number of electrodes and diagnostic tool for monitoring the delamination of CFRP laminates by changes in electrical resistance. Compos. Sci. Technol. 2001, 61, 1871-1880. [CrossRef]

26. Gaztelumendi, I.; Chapartegui, M.; Seddon, R.; Flórez, S.; Pons, F.; Cinquin, J. Enhancement of electrical conductivity of composite structures by integration of carbon nanotubes via bulk resin and/or buckypaper films. Compos. Part B Eng. 2017, 122, 31-40. [CrossRef]

27. Kulakov, V.; Aniskevich, A.; Ivanov, S.; Poltimäe, T.; Starkova, O. Effective electrical conductivity of carbon nanotube-epoxy nanocomposites. J. Compos. Mater. 2016, 51. [CrossRef]

28. Gardea, F.; Lagoudas, D.C. Characterization of electrical and thermal properties of carbon nanotube/epoxy composites. Compos. Part B Eng. 2014, 56, 611-620. [CrossRef]

29. Wichmann, M.; Sumfleth, J.; Gojny, F.H.; Quaresimin, M.; Fiedler, B.; Schulte, K. Glass-fibre-reinforced composites with enhanced mechanical and electrical properties-Benefits and limitations of a nanoparticle modified matrix. Eng. Fract. Mech. 2006, 73, 2346-2359. [CrossRef]

30. Sika Baltic. Biresin ${ }^{\circledR}$ CR122 Composite Resin System, Technical Data Sheet; Sika Deutschland GmbH: Bad Urach, Germany, 2020; p. 10.

31. Nanocyl SA. NC7000 ${ }^{\mathrm{TM}}$ Multiwall Carbon Nanotubes, Technical Data Sheet; Rue de l'Essor: Sambreville, Belgium, $2021 ; \mathrm{p} .4$.

32. Havel Composites CZ Company Ltd. Glass Unidirectional Fibres, Connected by a Grid $500 \mathrm{~g} / \mathrm{m} 2$, Technical Data Sheet; Havel Composites CZ Company Ltd: Svésedlice, Czech Republic, 2021; p. 5.

33. Pal, R. On the Electrical Conductivity of Particulate Composites. J. Compos. Mater. 2007, 41, 2499-2511. [CrossRef]

34. Aniskevich, K.; Starkova, O.; Jansons, J.; Aniskevich, A. Long-Term Deformability and Aging of Polymer Matrix Composites; Nova Science Publishers: New York, NY, USA, 2012; pp. 1-190.

35. Christensen, R.; McCoy, J. Mechanics of Composite Mateials. J. Appl. Mech. 1980, 47, 460. [CrossRef]

36. Aniskevich, A.N.; Jansons, J. Structural approach to calculation of the effect of moisture on elastic characteristics of organoplastics. Mech. Compos. Mater. 1998, 34, 383-386. [CrossRef]

37. Walmsley, P.; Fisher, I.R. Determination of the resistivity anisotropy of orthorhombic materials via transverse resistivity measurements. Rev. Sci. Instrum. 2017. [CrossRef] [PubMed]

38. Singh, Y. Electrical Resistivity Measurements: A Review. Int. J. Mod. Phys. Conf. Ser. 2013, 22, 745-756. [CrossRef]

39. Garcia Asuero, A.; Sayago, A.; González, G. The Correlation Coefficient: An Overview. Crit. Rev. Anal. Chem 2006, 36, 41-59. [CrossRef] 